UDC 539.3

\title{
A VARIATIONAL APPROACH TO STRAIN GRADIENT DAMAGE MECHANICS WITH AN APPLICATION TO COMPRESSED FRAMES*
}

\author{
Barchiesi E. ${ }^{1,2}$, Placidi L. ${ }^{1,3}$, Modin I.A. ${ }^{4}$, \\ Zhegalov D.V. ${ }^{4}$, Grigoryev M.V. ${ }^{4}$
}

${ }^{1}$ International Research Center for the Mathematics and Mechanics of Complex Systems Università degli Studi dell'Aquila, L'Aquila, Italia

${ }^{2}$ Dipartimento di Ingegneria Strutturale e Geotecnica, Università degli Studi di Roma "La Sapienza", Roma, Italia

${ }^{3}$ Faculty of Engineering, International Telematic University Uninettuno, Roma, Italia

${ }^{4}$ Research Institute for Mechanics, National Research Lobachevsky State University of Nizhny Novgorod, Nizhny Novgorod, Russian Federation

barchiesiemilio@gmail.com; 1.placidi@uninettunouniversity.net

Received by the Editor 2018/07/03

Irreversible phenomena such as corrosion or micro-cracks formation influence the load bearing capacity of a material. We will present a mechanical modelling, based on a variational approach, for dissipative phenomena in damaged strain gradient materials. In particular, we will consider the case of an evolving microstructure due to damage progression. Strain gradient regularization is adopted to model damage and we aim at studying quasi-static damage propagation in a 2D geometrically linear isotropic continuum by means of a variational inequality formulation. The novelty of this analysis is in the use of the total deformation energy as a functional, whose surface density depends upon the strain gradient. The total deformation energy functional includes a contribution due to the dissipation energy, a contribution due to the elastically stored energy and a contribution due to the work made by generalized forces onto the system. The dissipation energy does not depend upon the gradient or the Laplacian of the damage field. The non-locality is given by the dependence of the elastic strain energy density upon the second gradient of the displacement. Both first and second gradient elastic moduli are assumed to depend upon the scalar damage field. Results from numerical simulations will be presented and the crucial role of the inclusion of higher gradient terms in the energy will be discussed.

Keywords: mechanical modeling, variational approach, damage, gradient materials, numerical simulations, frames.

\section{Introduction}

The theory of damaged materials is concerned with the modelling of those dissipative phenomena, as corrosion and micro-cracks formation, which influence the load bearing

${ }^{*}$ This work was supported by a grant from the Goverment of the Russian Federation (contract No 14. Y26.31.0031). 
capacity of a material. The idea that continuum modelling is the most feasible approach to deal with such problem is spread in literature [1-8]. In order to account for the aforementioned irreversible phenomena, it is customary to complement the kinematics of the continuous system, which is usually given by the displacement function, with an additional field, which stands for the state of degradation. Such field, which is to be referred to in what follows as the damage field, usually ranges from 0 to 1 . This last two values stand, respectively, for the material's undamaged state and its failiure. In this presentation, damage field is assumed to be entropic, with the idea that such field is monotonic in time and healing is not to be contemplated. It is well-known that, when dealing with the classical Cauchy theory of elasticity, the presence of localized deformations, which are very often preferential from an energetic point of view, can be witnessed. Such localized deformations, which can not be handled by a model without an internal length controlling the size of boundary layers, lead unavoidably to mesh dependent simulations. Moreover, the size of boundary layers is a material characteristic and in the framework of continuum mechanics it is necessary, therefore, to introduce a characteristic length in the model to penalize those deformations characterized by a strong concentration. Starting from these considerations, a moltitude of non-local damage models have been proposed in the literature. In damage gradient models, and in particular in phase-field models, the internal energy is assumed to depend upon the damage first gradient [9-12]. There exist strong evidences, e.g. in Andrieux and Lorentz [13], that a regularization through the introduction of the gradient of damage allows to overcome issues related to localization and mesh-dependency. Herein, following some of our previous works [14-17], we analyze the possibility of regularizing the problem by including in the strain energy density a contribution due to the strain gradient. Being easy to motivate from the physical point of view, it is not unexpected that the idea of non-locality of damage encoded in the displacement field (in particular, by means of its second spatial derivative) is already present in the literature (see [18-20]). Indeed, it is possible to model a damaged material, for any loading stage, as a microstructured material, where the damage can be responsible of diminishing or emphasizing the material characteristic length. Furthermore, the relation between the microstructure of elastic materials and its non-negligible macroscopic effects has been extensively studied during the 60's [21-26] (even if higher gradient continua were known at least in 1800s, see [27-29]) where strain gradient models are a customary choice [30-37]. Athough a common critic to variational principles is their impossibility to describe non-conservative phenomena and, as a consequence, to model dissipation, it is possible to find in the literature several applications of variational formulations based on the Extended Rayleigh - Hamilton Principle to a wide class of dissipative phenomena. Moreover, already in 1948 Hill [38] proposed a formulation based on a variational inequality, which is known as maximum plastic work [39]. Further efforts aimed at developing a variational formulation of damage gradient models have been made in [7, 40-44]. Starting from these results, in this paper, as in [14-17], strain gradient regularization is adopted to model damage and we aim at studying quasi-static damage propagation in a 2D geometrically linear isotropic continuum by means of a variational inequality formulation. The novelty of this analysis is in the use of the total deformation energy as a functional, whose surface density depends upon the strain gradient rather than Laplacian and/or gradient of the damage field. In this way, Karush - Kuhn - Tucker (KKT) conditions describing the damage evolution and the classical (generalized) balance equations can be derived. In particular, the total deformation energy functional includes not only a 
contribution due to the elastically stored energy and a contribution due to the work made by external (generalized) forces onto the system, but also a contribution due to the dissipation energy. The dissipation energy does not depend upon the gradient or the Laplacian of the damage field; the non-locality is given by the dependence of the elastic strain energy density upon the second gradient of the displacement. Both first and second gradient elastic moduli are assumed to depend upon the scalar damage field. The ratio between these second and first gradient constitutive coefficients gives, roughly speaking, the desired squared length scale of the material. Usually, the first gradient elastic coefficients (the Lamé constants) are assumed to decrease with damage and to be zero at the failure point, when damage is equal to one. On the one hand, in [14-17] the second gradient elastic coefficients have been assumed to increase with damage, because damage has been assumed to emphasize the microstructure and, hence, also the characteristic length scale of the material. On the other hand, in this paper we are in the context of fracture mechanics and we are are going to consider the case where almost no elastic potential energy is stored in the fracture region. Thus, also the second gradient elastic coefficients are here assumed to decrease with damage and to be zero at the failure point, when damage is equal to one. As we stated above, the model is presented and solved in a geometrically linear setting for an isotropic 2D body, even if further generalizations in this respect, like the inclusion of anisotropy and 3D geometries, and the introduction of tension/compression damage criteria based upon strain invariants are achievable without any relevant conceptual challenge. We further expect this formulation, if properly adapted to account for plastic effects (see for instance Reddy $[45,46]$ and $[14,15]$ ), to be suitable to study ductile fracture. The outcome of our investigation is that the energy method employed herein for the study of quasi-static propagation of brittle fracture in the setting of strain gradient modelling, with the damage field being just a local variable, is able to handle damage initiation and propagation, with the microstructure eventually evolving as a consequence of that, in an effective and efficient way.

\section{Variational formulation of the problem}

Let us introduce the kinematic fields

$$
u:\left(\mathbb{R}^{2} \supseteq \mathfrak{B},[0, T]\right) \rightarrow \mathbb{R}^{2},
$$

which is the displacement function (being $\mathfrak{B}$ the reference shape of the body and $T$ the time horizon), and the damage function

$$
\omega:\left(\mathbb{R}^{2} \supseteq \mathfrak{B},[0, T]\right) \rightarrow[0,1] .
$$

As healing is not considered here, we assume that

$$
\dot{\omega} \geq 0 \text {, }
$$

where dot represents time derivative. We now adopt the so-called maximum energy release rate variational principle for dissipative systems, which reads as

$$
\delta \varepsilon(u, \omega, \dot{u}, \dot{\omega}) \leq \delta \varepsilon(u, \omega, \nu, \beta) \text { for all } v \text { and for all } \beta \geq 0,
$$

with $\delta \varepsilon(u, \omega, \delta u, \delta \omega)$ being the functional derivative of $\varepsilon$ along the direction $(\delta u, \delta \omega)$ in $(u, \omega)$, and $\varepsilon$ being the total energy functional. Such functional, in the quasi-static case that we consider here (no dependence upon the rate of any kinematic quantity), reads as the sum of two additive contributions: the recoverable potential energy, given by the 
difference between the internal stored strain energy $\int_{\mathfrak{B}} U_{e}(G, \nabla G, \omega) d A$ and the work done by (generalized) external actions $b^{\text {ext }}$ (bulk force), $m^{\text {ext }}$ (bulk double force), $\tau^{\text {ext }}$ (traction, i.e. line force), $t^{\text {ext }}$ (line double force), and $f^{\text {ext }}$ (point force)

$$
\int_{\mathfrak{B}}\left[U_{e}(G, \nabla G, \omega)-b^{\mathrm{ext}} u-m^{\mathrm{ext}} \nabla u\right] d A-\int_{\partial \mathfrak{B}}\left[t^{\mathrm{ext}} u+\tau^{\mathrm{ext}}[(\nabla u) n]\right] d s-\int_{\partial \partial \mathfrak{B}} f^{\mathrm{ext}} u
$$

and the dissipation energy

$$
\int_{\mathfrak{B}} \frac{k}{2} \omega^{2} d A
$$

As for simplicity we are considering a 2D isotropic homogenous elastic medium for what concerns the recoverable part of the energy, we have

$$
\begin{aligned}
& U_{e}(G, \nabla G, \omega)= 2 \mu G_{12}^{2}+\frac{1}{2} \lambda\left(G_{11}+G_{22}\right)^{2}+\mu\left(G_{11}^{2}+G_{22}^{2}\right)+\frac{B}{2}\left(G_{11,1}^{2}+G_{22,2}^{2}\right)+ \\
&+2 A\left(G_{12,1}^{2}+G_{12,2}^{2}\right)+\left(\frac{3 A}{2}-B+C+2 D\right)\left(G_{11,2}^{2}+G_{22,1}^{2}\right)+ \\
&+(A+B-2 C)\left(G_{11,1}^{2} G_{12,2}^{2}+G_{12,1}^{2} G_{22,2}^{2}\right)+ \\
&+(-4 A+2 B-4 D)\left(G_{12,2}^{2} G_{22,1}^{2}+G_{11,2}^{2} G_{12,1}^{2}\right)+ \\
&+\left(-\frac{A}{2}-\frac{B}{2}+C+2 D\right)\left(G_{11,2}^{2} G_{22,2}^{2}+G_{11,1}^{2} G_{22,1}^{2}\right),
\end{aligned}
$$

where comma followed by an index represents the spatial derivative with respect to the indexed direction, with $\mu$ and $\lambda$ being the standard Lamé coefficients and $A, B, C, D$ being higher gradient constitutive coefficients. For simplicity, the following linear dependence of such coefficients upon damage is postulated for the Lamé coefficients

$$
\lambda=\lambda_{0}(1-\omega), \quad \mu=\mu_{0}(1-\omega)
$$

and for the higher gradient constitutive coefficients

$$
A=A_{0}(1+n \omega), \quad B=B_{0}(1+n \omega), \quad C=C_{0}(1+n \omega), \quad D=D_{0}(1+n \omega), \quad n \in \mathbb{R} .
$$

Clearly, if $\delta \omega=0$ is considered in the maximum energy release rate, the standard stationarity principle can be recovered, as no dissipation is entailed by such condition, i.e.

$$
\delta \varepsilon(u, \omega, \delta u, \delta \omega)=0
$$

which, after a sequence of integration by parts, gives the following standard internal equilibrium equations using the Einstein summation convention

$$
\left(S_{i j}-T_{i j h, h}\right)_{, j}+b_{i}^{\text {ext }}-m_{i j, j}^{\text {ext }}=0 \text { for all } X \in \mathfrak{B}
$$

with

$$
S_{i j}=\frac{\partial U}{\partial G_{i j}}, \quad T_{i j h}=\frac{\partial U}{\partial G_{i j, h}}
$$

being these last two quantities, respectively, the Piola second-order stress tensor and the third-order hyper-stress tensor. Clearly, as the integration by parts proceeds, new boundary terms emerge and give, together with the initially present boundary terms, the boundary conditions (for more details see [35, 47]). 
Exploiting the maximum energy release rate principle in its general form, i.e. for general admissible variations, after some standard localization arguments, the following KarushKuhn-Tucker conditions for damage mechanics can be derived (for a compact notation, the addition of the recoverable energy density with the dissipation energy density is denoted with $U$ )

$$
\frac{\partial U}{\partial \omega} \dot{\omega}=0 \text { for all } X \in \mathfrak{B} .
$$

Clearly, as $\omega$ has been assumed to be monotonically increasing in time, we have that

$$
\frac{\partial U}{\partial \omega}=0 \vee \dot{\omega}=0 \text { for all } X \in \mathfrak{B} \text {. }
$$

Such condition is implemented in a solution algorithm in the following straightforward manner. First, the damage threshold $\bar{\omega}$ is defined as

$$
\begin{gathered}
\bar{\omega}(X, t)=\frac{\lambda_{0}+2 \mu_{0}}{k}\left(u_{1,1}^{2}+u_{2,2}^{2}\right)+2 \frac{\mu_{0}}{k} u_{1,2} u_{2,1}+\frac{\mu_{0}}{k}\left(u_{1,2}^{2}+u_{1,1}^{2}\right) 2 \frac{\lambda_{0}}{k} u_{1,1} u_{2,2}- \\
-n \frac{A_{0}}{k}\left(u_{1,22}^{2}+u_{2,11}^{2}\right)-n \frac{B_{0}}{k}\left(u_{1,11}^{2}+u_{2,22}^{2}\right)-n \frac{C_{0}}{k}\left(u_{1,12}^{2}+u_{2,12}^{2}\right)- \\
\quad-2 n \frac{D_{0}}{k}\left(u_{1,11} u_{2,12}+u_{2,22} u_{1,12}\right)- \\
-n \frac{B_{0}-C_{0}+A_{0}}{k}\left(u_{1,11} u_{1,22}+u_{2,11} u_{2,22}\right)- \\
-2 n \frac{B_{0}-A_{0}-D_{0}}{k}\left(u_{1,12} u_{2,11}+u_{1,22} u_{2,12}\right),
\end{gathered}
$$

being the solution of

$$
\frac{\partial U}{\partial \omega}(G, \nabla G, \bar{\omega}(G, \nabla G))=0 .
$$

Then, the following iterative procedure is considered, where the index represents the time discretization

$$
\begin{gathered}
u(X, 0)=u_{0}(X)=0 \text { for all } X \in \mathfrak{B}, \quad \omega(X, 0)=\omega_{0}=0 \text { for all } X \in \mathfrak{B}, \\
u_{i}=\arg \min _{u: \mathfrak{B} \rightarrow \mathbb{R}^{2}} \varepsilon\left(u, \omega_{i-1}\right), \\
\omega_{i}=\max \left(\bar{\omega}\left(G_{i}, \nabla G_{i}\right), \omega_{i-1}\right) .
\end{gathered}
$$

\section{Numerical results}

We now show some numerical results obtained by means of the presented method. The algorithm which has been described sinthetically above has been implemented by means of the software LiveLink for connecting Matlab (loop implementation) and Comsol (finite element minimization routine). A square frame (it is possible to distinguish two boundaries, an internal one of size $0.0178 \times 0.078 \mathrm{~m}$ and an external one $0.02 \mathrm{~m} \times 0.02 \mathrm{~m}$ ) is subject to the following boundary conditions: the bottom external side is forced to have a vanishing displacement in the vertical direction, while the upper external side has a 
vertical prescribed displacement toward the bottom. The other boundaries are free. The results of the analysis are plotted in Fig. 1-4.
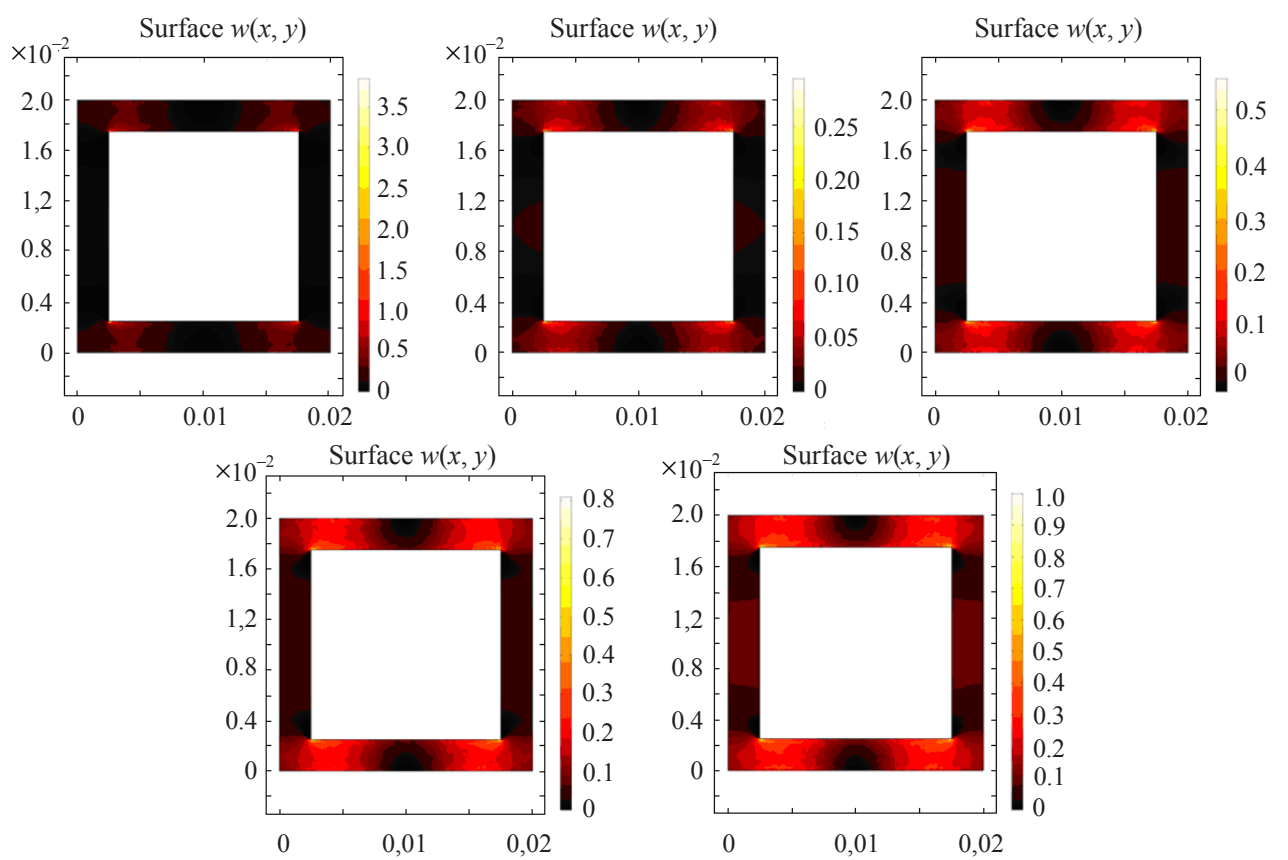

Fig. 1. Qualitative progression of damage in five relevant time instants
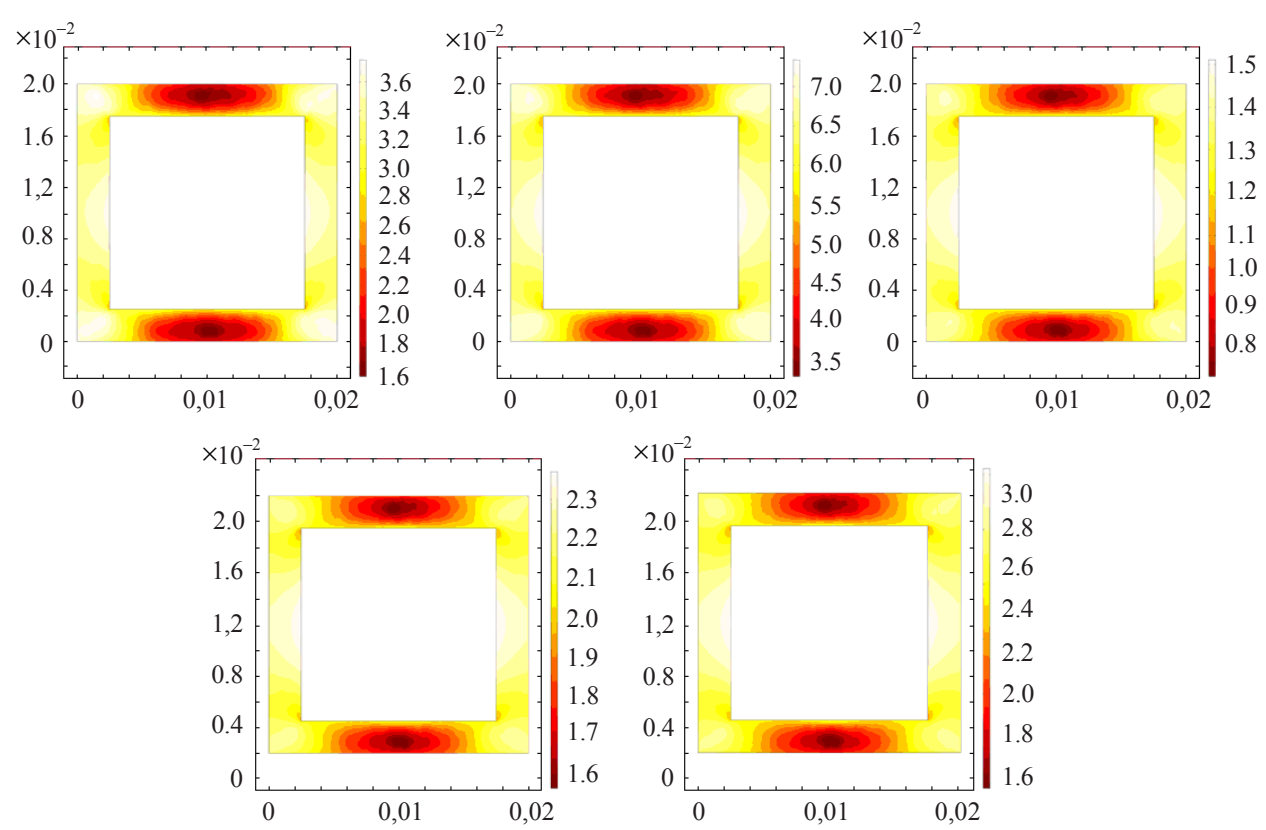

Fig. 2. Qualitative advancement of $u_{1,1}$ in five relevant time instants 

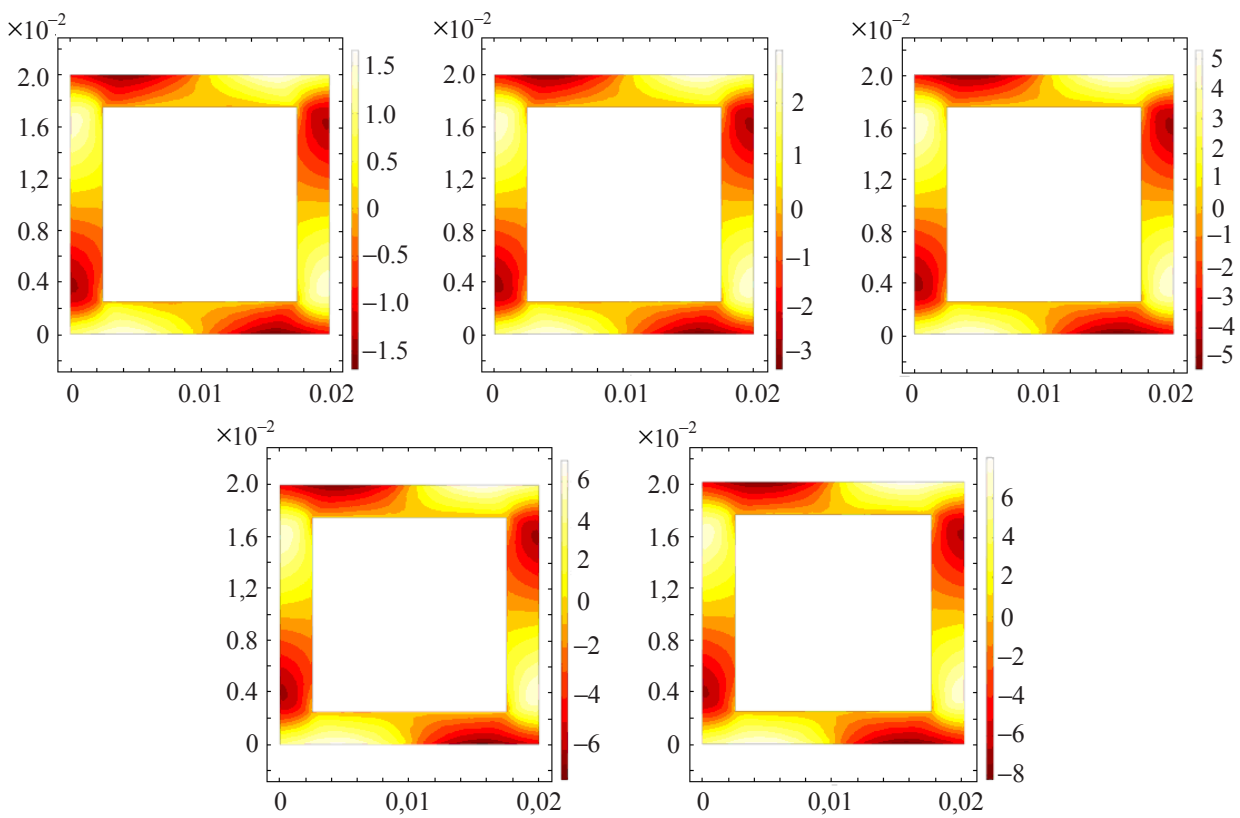

Fig. 3. Qualitative advancement of $\left(u_{1,2}+u_{2,1}\right) / 2$ in five relevant time instants

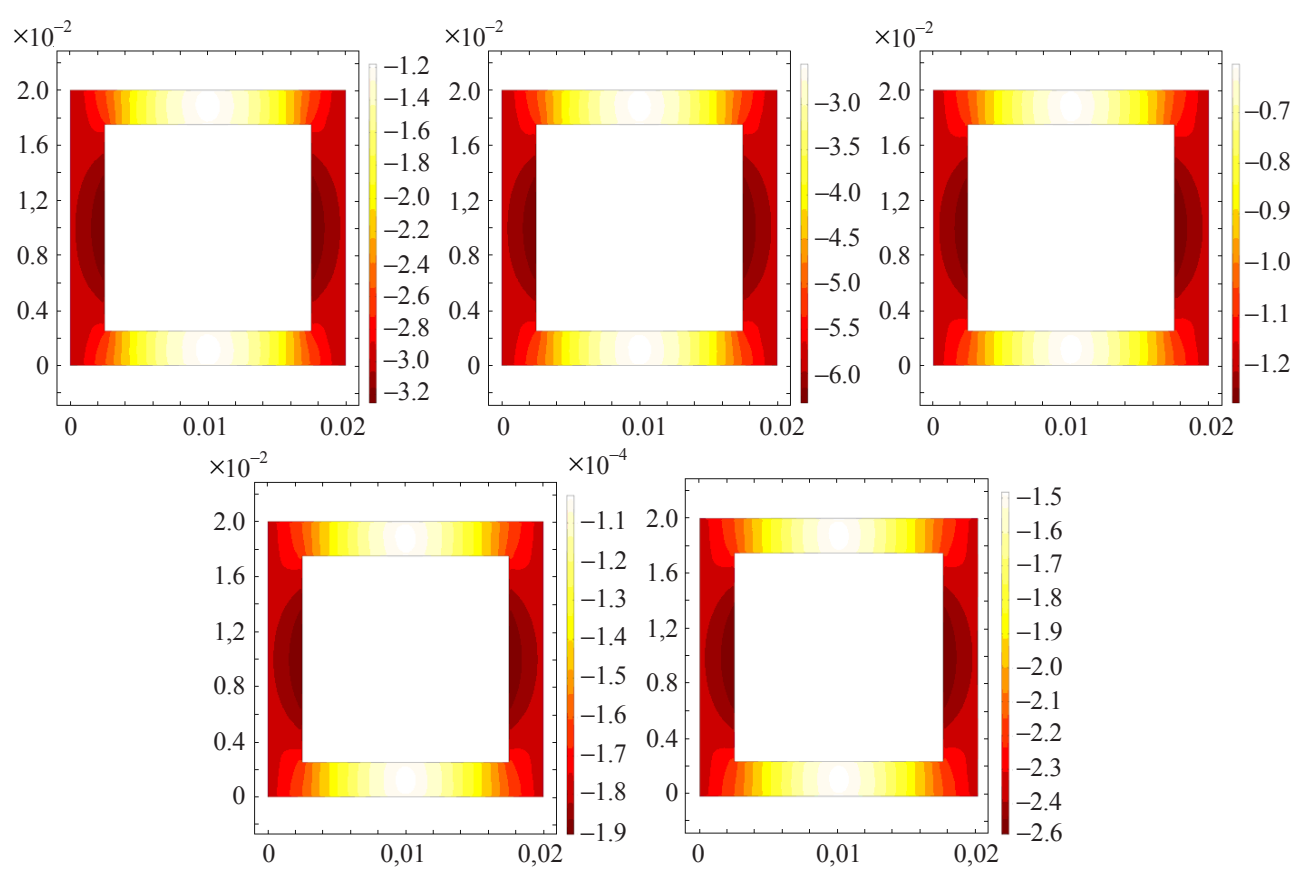

Fig. 4. Qualitative advancement of $u_{2,2}$ in five relevant time instants

\section{Conclusions}

In this paper we have shortly presented a variational approach for the mechanical modelling of dissipative phenomena in materials with evolving microstructure. Not only the load 
bearing capacity of the materiali is obviously influenced by damage progression, but also its microstructure is affected. Some numerical simulations have been finally presented to give an idea of the effectiveness of the proposed approach. Indeed, without the inclusion of higher gradient terms, the previously shown simulations would exhibit a mesh-dependent strain (and, subsequently, damage) concentration in the four internal corners of the considered frame.

\section{References}

1. Contrafatto L., Cuomo M., Gazzo S. A concrete homogenisation technique at meso-scale level accounting for damaging behaviour of cement paste and aggregates. Computers \& Structures. 2016. Vol. 173. P. 1-18.

2. Cuomo M., Contrafatto L., Greco L. A variational model based on isogeometric interpolation for the analysis of cracked bodies. International Journal of Engineering Science. 2014. Vol. 80. P. $173-188$.

3. Cuomo M., Greco L. Isogeometric analysis of space rods: Considerations on stress locking. ECOCOMAS 2012. Vieva, Austria, September 10-14. 2012.

4. Amor H., Marigo J.-J., Maurini C. Reguralized formulation of the variational brittle fracture with unilateral contact: numerical experiment. Journal of the Mechanics and Physics of Solids. 2009. Vol. 57. Iss. 8. https://doi.org/10.1016/j.jmps.2009.04.011

5. Bourdin B., Francfort G.A., Marigo J.-J. The variational approach to fracture. Journal of Elasticity. 2008. Vol. 91. DOI: 10.1007/s10659-007-9107-3

6. Pham K., Marigo J.-J. Approche variationnelle de l'endommagement: II. Les modeles a gradient. Comptes Rendus Mécanique. 2010. Vol. 338. Iss. 4. P. 199-206.

7. Placidi L. A variational approach for a nonlinear 1-dimensional second gradient continuum damage model. Continuum Mechanics and Thermodynamics. 2015 Vol. 27. Iss. 4-5. P. 623-638.

8. Placidi L., Barchiesi E., Misra A. A strain gradient variational approach to damage. A comparison with damage gradient models and numerical results. Mathematics and Mechanics of Complex Systems. 2018. Vol. 6. Iss. 2. P. 77-100.

9. Miehe C., Aldakheel F., Raina A. Phase field modeling of ductile fracture at finite strains: A variational gradient-extended plasticity-damage theory. International Journal of Plasticity. 2016. Vol. 84. P. 1-32.

10. Contrafatto L., Cuomo M. A framework of elastic-plastic damaging model for concrete under multiaxial stress states. International Journal of Plasticity. 2006. Vol. 22. No 12. P. 2272-2300.

11. Pham K., Marigo J.-J. Approche variationnelle de l'endommagement: I. les concepts fondamentaux. Comptes Rendus Mécanique. 2010. Vol. 338. Iss. 4. P. 191-198.

12. Miehe C., Hofacker M., Welschinger F. A phase field model for rate-independent crack propagation: Robust algorithmic implementation based on operator splits. Computer Methods in Applied Mechanics and Engineering. 2010. Vol. 199. No 45. P. 2765-2778.

13. Marigo J.-J., Maurini C., Pham K. An overview of the modelling of fracture by gradient damage models. Meccanica. 2016. Vol. 51. P. 3107-3128.

14. Placidi L., El Dhaba A.R. Semi-inverse method a la saint-venant for two-dimensional linear isotropic homogeneous second-gradient elasticity. Mathematics and Mechanics of Solids. 2017. Vol. 22. Iss. 5. P. 919-937.

15. Placidi L., Misra A., Barchiesi E. Two-dimensional strain gradient damage modeling: a variational approach. Zeitschrift für angewandte Mathematik und Physik. 2018. Vol. 69. Iss. 3. P. 56.

16. Rahali Y., Giorgio I., Ganghoffer J.F., dell'Isola F. Homogenization a la Piola produces second gradient continuum models for linear pantographic lattices. International Journal of Engineering Science. 2015. Vol. 97. P. 148-172.

17. Reddy B.D. The role of dissipation and defect energy in variational formulations of problems in strain-gradient plasticity. Part 2: single-crystal plasticity. Continuum Mechanics and Thermodynamics. 2011. Vol. 23. Iss. 6. P. 551-572.

18. Pham K., Amor H., Marigo J.-J., Maurini C. Gradient damage models and their use to approximate brittle fracture. International Journal of Damage Mechanics. 2011. Vol. 20. Iss. 4. P. 618-652.

19. Oliver-Leblond C., Dumontet H., Kondo D. A micro-mechanics based strain gradient 
damage model: Formulation and solution for the torsion of a cylindrical bar. European Journal of Mechanics-A/Solids. 2016. Vol. 56. P. 19-30.

20. Peerlings R.H.J., Geers M.G.D., De Borst R., Brekelmans W.A.M. A critical comparison of nonlocal and gradient-enhanced softening continua. International Journal of solids and Structures. 2001. Vol. 38. Iss. 44-45. P. 7723-7746.

21. Zybell L., Mühlich U., Kuna M. Constitutive equations for porous plane-strain gradient elasticity obtained by homogenization. Archive of Applied Mechanics. 2009. Vol. 79. Iss. 4. P. 359-375.

22. Misra A., Singh V. Micromechanical model for viscoelastic materials undergoing damage. Continuum Mechanics and Thermodynamics. 2013. Vol. 25. Iss. 2-4. P. 343-358.

23. Eremeyev V.A., Pietraszkiewicz W. Material symmetry group and constitutive equations of micropolar anisotropic elastic solids. Mathematics and Mechanics of Solids. 2016. Vol. 21. No 2. P. 210-221.

24. Eremeyev V.A., dell'Isola F., Boutin C. Linear pantographic sheets: existence and uniqueness of weak solutions. Journal of Elasticity. 2017. Vol. 132. Iss. 2. P. 175-196.

25. Forest S. Micromorphic approach for gradient elasticity, viscoplasticity, and damage. Journal of Engineering Mechanics. 2009. Vol. 135. No 3. P. 117-131.

26. Eremeyev V.A., Lebedev L.P., Altenbach H. Foundations of Micropolar Mechanics. Springer Science \& Business Media. 2012. 81 p.

27. Dell'Isola F., Placidi L. Variational principles are a powerful tool also for formulating feld theories. In Variational models and methods in solid and fuid mechanics. Springer. 2011. P. 1-15.

28. Dell'Isola F., Della Corte A., Giorgio I. Higher-gradient continua: The legacy of Piola, Mindlin, Sedov and toupin and some future research perspectives. Mathematics and Mechanics of Solids. 2017. Vol. 22. Iss. 4. P. 852-872.

29. Dell'Isola F., Madeo A., Seppecher P. Cauchy tetrahedron argument applied to higher contact interactions. Archive for Rational Mechanics and Analysis. 2016. Vol. 219. Iss. 3. P. 1305-1341.

30. Greco L., Cuomo M. B-spline interpolation of Kirchhoff-Love space rods. Computer Methods in Applied Mechanics and Engineering. 2013. Vol. 256. P. 251-269.

31. Placidi L., Rosi G., Giorgio I., Madeo A. Reflection and transmission of plane waves at surfaces carrying material properties and embedded in second-gradient materials. Mathematics and Mechanics of Solids. 2014. Vol. 19. Iss. 5. P. 555-578.

32. Thiagarajan G., Misra A. Fracture simulation for anisotropic materials using a virtual internal bond model. International Journal of Solids and Structures. 2004. Vol. 41. Iss. 11. P. 2919-2938.

33. Kiendl J., Ambati M., De Lorenzis L., Gomez H., Reali A. Phase-field description of brittle fracture in plates and shells. Computer Methods in Applied Mechanics and Engineering. 2016. Vol. 312. P. 374-394.

34. Abali B.E., Müller W.H., Eremeyev V.A. Strain gradient elasticity with geometric nonlinearities and its computational evaluation. Mechanics of Advanced Materials and Modern Processes. 2015. Vol. 1. Iss. 1. DOI: 10.1186/s40759-015-0004-3

35. Reiher J.C., Giorgio I., Bertram A. Finite-element analysis of polyhedra under point and line forces in second-strain gradient elasticity. Journal of Engineering Mechanics. 2016. Vol. 143. Iss. 2. P. 04016112.

36. Rudraraju S., Van der Ven A., Garikipati K. Three-dimensional isogeometric solutions to general boundary value problems of toupin's gradient elasticity theory at finite strains. Computer Methods in Applied Mechanics and Engineering. 2014. Vol. 278. P. 705-728.

37. Auffray N., Dirrenberger J., Rosi G. A complete description of bi-dimensional anisotropic strain-gradient elasticity. International Journal of Solids and Structures. 2015. Vol. 69-70. P. 195-206.

38. Hill R. A variational principle of maximum plastic work in classical plasticity. The Quarterly Journal of Mechanics and Applied Mathematics. 1948. DOI: 10.1093/qjmam/1.1.18

39. Javili A., dell'Isola F., Steinmann P. Geometrically nonlinear higher-gradient elasticity with energetic boundaries. Journal of the Mechanics and Physics of Solids. 2013. Vol. 6. No 12. P. 2381-2401.

40. Bourdin B., Larsen C., Richardson C. A time-discrete model for dynamic fracture based on crack regularization. International journal of fracture. 2011. Vol. 168. No 2. P. 133-143. 
41. Andreaus U., dell'Isola F., Giorgio I., Placidi L., Lekszycki T., Rizzi N.L. Numerical simulations of classical problems in two-dimensional (non) linear second gradient elasticity. International Journal of Engineering Science. 2016. Vol. 108. P. 34-50.

42. Pham K., Marigo J.-J., Maurini C. The issues of the uniqueness and the stability of the homogeneous response in uniaxial tests with gradient damage models. Journal of the Mechanics and Physics of Solids. 2011. Vol. 59. Iss. 6. P. 1163-1190.

43. Placidi L. A variational approach for a nonlinear one-dimensional damage-elasto-plastic secondgradient continuum model. Continuum Mechanics and Thermodynamics. 2016. Vol. 28. Iss. 1-2. P. 119-137.

44. Placidi L., Andreaus U., Giorgio I. Identification of two-dimensional pantographic structure via a linear D4 orthotropic second gradient elastic model. Journal of Engineering Mathematics. 2017. Vol. 103. Iss. 1. P. 1-21.

45. Sicsic P., Marigo J.-J. From gradient damage laws to Griffith's theory of crack propagation. Journal of Elasticity. 2013. Vol. 113. Iss. 1. P. 55-74.

46. Stolk J., Verdonschot N., Mann K.A., Huiskes R. Prevention of mesh-dependent damage growth in finite element simulations of crack formation in acrylic bone cement. Journal of Biomechanics. 2003. Vol. 36. Iss. 6. P. 861-871.

47. Dell'Isola F., Maier G., Perego U., Andreaus U., Esposito R., Forest S. The Complete Works of Gabrio Piola: Volume I. Cham. Switzerland. Springer. 2014. 813 p.

\title{
ВАРИАЦИОННЫЙ ПОДХОД К ГРАДИЕНТНОЙ МЕХАНИКЕ ПОВРЕЖДЕННОЙ СРЕДЫ С ПРИМЕНЕНИЕМ К СЖАТЫМ РАМАМ
}

\author{
Баркиези Е. ${ }^{1,2}$, Плачиди Л. ${ }^{1,3}$, Модин И.А. ${ }^{4}$ Жегалов Д.В. ${ }^{4}$, Григорьев М.В. ${ }^{4}$ \\ ${ }^{1}$ Международный исследовательский цеентр математики и механики сложных систем, \\ университет Л'Акуила, Л'Акуила, Италия \\ ${ }^{2}$ Отдел структурной и геотехнической инженерии, Римский университет \\ Ла Сапиениа, Рим, Италия \\ ${ }^{3}$ Факультет инженерии, Международный телематический университет Uninettuno, \\ Рим, Италия \\ ${ }^{4}$ Научно-исследовательский институт механики Национального исследовательского \\ Нижегородского государственного университета им. Н.И. Лобачевского, \\ Нижний Новгород, Российская Федераичя
}

Необратимые явления, такие как коррозия или образование микротрещин, влияют на несущую способность материала. Для диссипативных явлений в поврежденных градиентных материалах представлено моделирование, основанное на вариационном подходе. В частности, рассмотрен случай развития микроструктуры, вызванной развитием поврежденности. Для моделирования поврежденности используется градиентная регуляризация. Изучается квазистатическое развитие поврежденности в двухмерном геометрически линейном изотропном континууме на основе вариационного неравенства. Новизна такого анализа заключается в использовании полной энергии деформации как функционала, поверхностная плотность которого зависит от градиента деформации. Функционал полной энергии деформации включает в себя составляющие, обусловленные энергией диссипации, упруго-накопленной энергией, а также работой, совершенной обобщенными силами над системой. Энергия диссипации не зависит от градиента или лапласиана поля поврежденности. Нелокальность обусловлена зависимостью плотности энергии упругой деформации от второго градиента перемещений. Подразумевается, что модули упругости первого и второго градиентов зависят от скалярного поля поврежденности. Представлены результаты численного моделирования. Обсуждена ключевая роль учета в функционале энергии градиентных членов высших порядков.

Ключевые слова: механическое моделирование, вариационный подход, поврежденность, градиентные материалы, численное моделирование, рамы. 